\title{
Sustainable coastal communities: the use of crenulate bay theory at different scales of coastal management
}

\author{
David S. Brew, Philip Williams \& Associates, 550 Kearny Street, Suite 900, San Francisco, CA 94108, \\ USA ${ }^{1}$., d.brew@royalhaskoning.com \\ Gregor Guthrie, Royal Haskoning, Rightwell House, Bretton, Peterborough, PE3 8DW, UK., \\ g.guthrie@royalhaskoning.com \\ Mike Walkden, Royal Haskoning, Stratus House, Emperor Way, Exeter, EX1 3QS, UK., \\ m.walkden@royalhaskoning.com
}

Robert T. Battalio, Philip Williams \& Associates, 550 Kearny Street, Suite 900, San Francisco, CA 94108, USA., b.battalio@pwa-Itd.com

Crenulate bay theory is well developed and natural examples of this type of bay are evident along many coasts. Case studies are presented here in which this theory has been applied and adapted at different scales to address the needs of management and coastal communities. In many places, these needs are not currently met because coastal protection is constraining landward shoreline movement, leading to erosion and consequential loss of property, infrastructure, public access and amenity value.

Abereiddy, in west Wales has a small locally important beach backed by a seawall. With no intervention, seawall collapse will lead to realignment and a more natural beach form, but a reduction in car parking area. Crenulate bay theory was applied to understand what shoreline shape would result if the seawall was lost. Coyote Point, in San Francisco Bay, California is a popular recreation area. Coastal defence structures are failing, leading to erosion of the coastal path and beach loss. In order to develop an innovative sustainable solution to the erosion problem, whilst maintaining recreational functions and good public access, crenulate bay setback options were examined.

These local examples can be set within the wider context of integrated coastal zone management. Axiomatic principles, such as crenulate bay theory, assist in interpreting existing broader-scale erosion monitoring in the context of geomorphological control. Examples are provided demonstrating regional benefits of the approach by taking a landscape-scale view of coastal evolution.

\section{Introduction}

A coast with constrained sediment supply between two erosion-resistant points (headlands or coastal structures) will adjust its shape to an orientation that is perpendicular to the main wave direction. Wave direction tends to vary across such bays, due to wave transformations in the lee of the headlands. Often the natural equilibrium shape of this type of shoreline is a log-spiral. This beach form has been recognised since at least the start of the $20^{\text {th }}$ century and has been given various names such as zeta bays (Halligan, 1906), half-heart bays (Silvester, 1960) and is now commonly known as 'crenulate'. For a detailed recent description see Hsu et al. (2008).

\section{Current address: Royal Haskoning, Rightwell House, Bretton, Peterborough, PE3 8DW, UK}


Knowledge that certain coasts are attracted towards this form can be extremely useful because it enables predictions of future state to be made over the medium to long term. These are scales at which numerical models struggle to provide meaningful predictions, yet are particular important to coastal management. The following examples illustrate how crenulate bay theory may be used at different scales and in different ways to inform coastal decision making.

\section{Abereiddy Beach, West Wales}

Abereiddy beach is around $200 \mathrm{~m}$ long and situated in a small bay facing west on the north Pembrokeshire coast in Wales. The beach is composed of gravel and rests on a gently sloping lower beach of fine sediment, which in turn rests on glacial clay. The beach is backed by a car park protected by a seawall (constructed from steel piles and intermittent timber sleepers), which is currently influencing the form of the beach. The car park is considered a valuable and well used amenity area. Several cottages are situated behind the southern section of the car park on slightly raised ground (Figure 1). The seawall currently provides limited resistance to wave attack, which has led to significant outwash of backing material. The continued existence of the seawall is now questionable, for reasons of sustainability and safety. There is concern that the loss of the existing defences would result in extensive loss of car park, and that subsequent erosion may impact the cottages. Equally, there is concern that reinforcing the wall will lead to further loss and deterioration of the amenity beach, negating the value of the car park and leading to a situation of increasing vulnerability to sudden failure in the future.

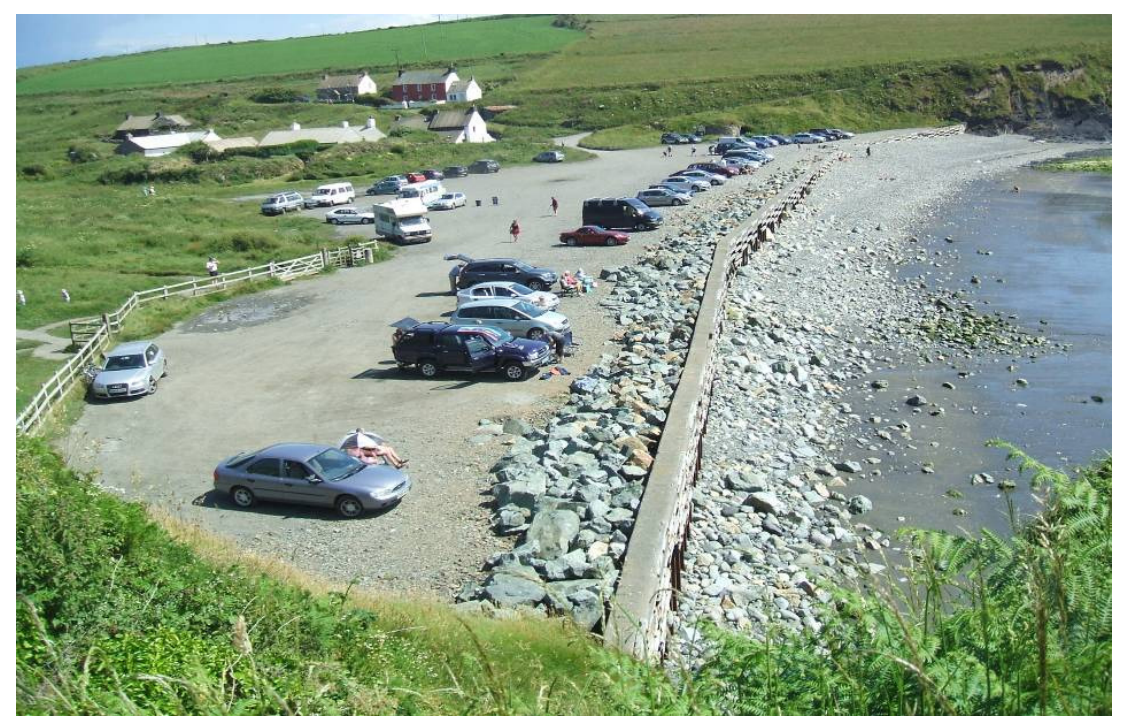

Fig. 1. Abereiddy beach and seawall in June 2009

Key questions for managers are: how would the beach respond should the seawall be removed or allowed to fail? what loss due to erosion would result? what is the risk to the cottages and access to the bay? and how recession might be reduced if the upper beach profile was steepened through the repositioning of the existing rock armour. The potential retreat of the beach was analysed for several sea-level rise scenarios and one armouring scenario, by 
estimating its natural profile and planform, and redistributing its current volume to fit within the resulting three-dimensional surface.

\subsection{Profiles}

The Abereiddy beach profiles are currently truncated by the seawall above, approximately, the $2 m$ contour. A profile from a comparable site was used to estimate its natural shape. Aber Mawr, which is around $9 \mathrm{~km}$ from Abereiddy, was identified as an appropriate beach. Some comparison was possible between the Aber Mawr profiles and the lower part of the Abereiddy beach. It was found that Abereiddy was steeper, and that this steepness varied. A scale factor (which was varied alongshore) was inferred from this comparison and used to increase the steepness of the Aber Mawr profile, to make it more representative. A copy of the resulting profiles was adapted to represent a beach with a rock armour crest. This was done by artificially steepening the upper section.

\subsection{Planform}

The current beach planform is complicated by the presence of the seawall (Figure 2). However, the curve of the contours below the seawall suggest that, in its natural condition, the beach would adopt a crenulate form. This was tested by fitting a log-spiral curve to the $2 \mathrm{~m}$ contour, which was approximately $180 \mathrm{~m}$ long. This level was chosen because it was the longest contour passing entirely along the beach. The shape fitting process resulted in the following log-spiral equation:

$$
r=21 e^{1.2} \quad \text { Equation } 1
$$

where $r$ is the radius. This form fitted the $2 \mathrm{~m}$ contour with a (rms) error of $0.59 \mathrm{~m}$, which is only $0.3 \%$ of the contour length, confirming the perception of a crenulate bay form.
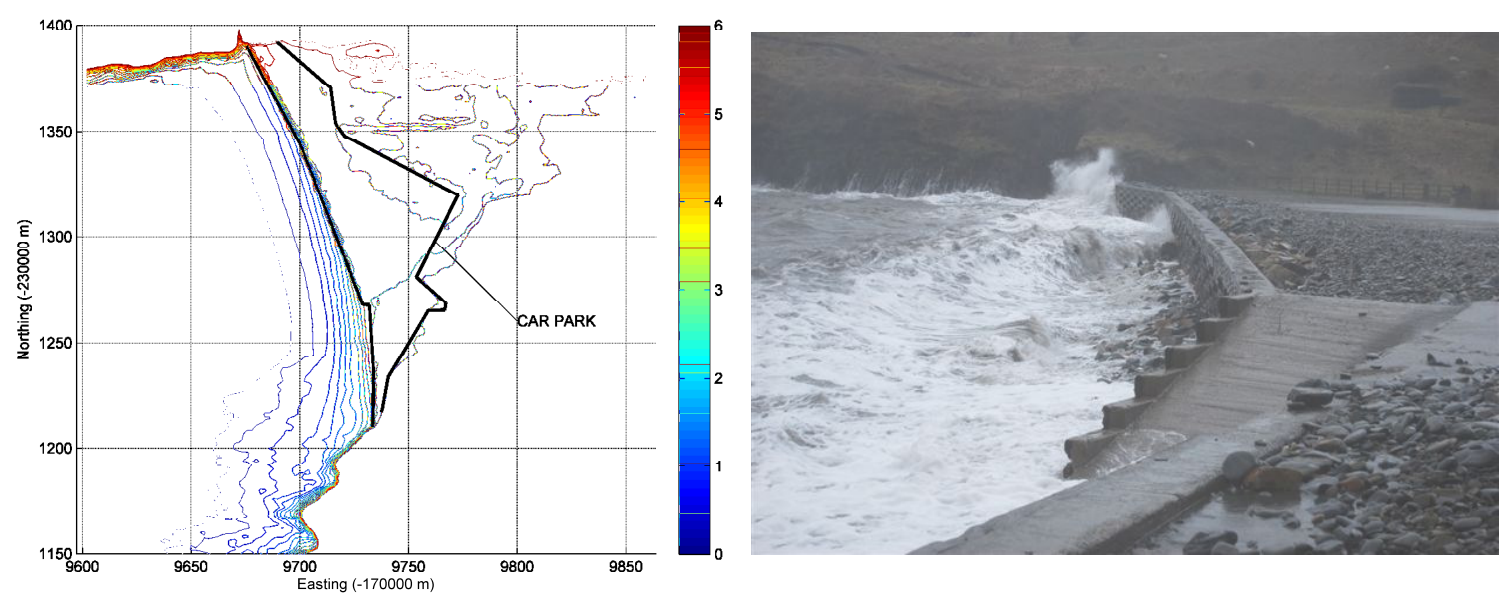

Fig. 2. Zero to six metre contours at Abereiddy beach and wave interaction with beach form. 


\subsection{Projections of Future Change}

To predict future alignments, assumptions were made that the $2 \mathrm{~m}$ contour would maintain the log-spiral form described by Equation 1 and would be free to migrate perpendicular to the general alignment of the beach. The two sets of derived profiles (natural and engineered) were then projected around the log-spiral contour, to form two synthetic three-dimensional beach surfaces. Three copies of the natural surface were then generated to represent profiles following increases in sea level of $0.36 \mathrm{~m}, 1.0 \mathrm{~m}$ and $2.0 \mathrm{~m}$. The lower two values were based on Defra projections of sea-level rise 50 and 100 years into the future. The highest value represented a possible upper limit in 100 years, as defined by UKCP09. These were produced by simply raising the beach surface by amounts equal to the assumed sea-level rise. The resulting five synthetic beach surfaces were then translated horizontally until the total volume of material encompassed by the surface was equal to the current beach volume (Figure 3).

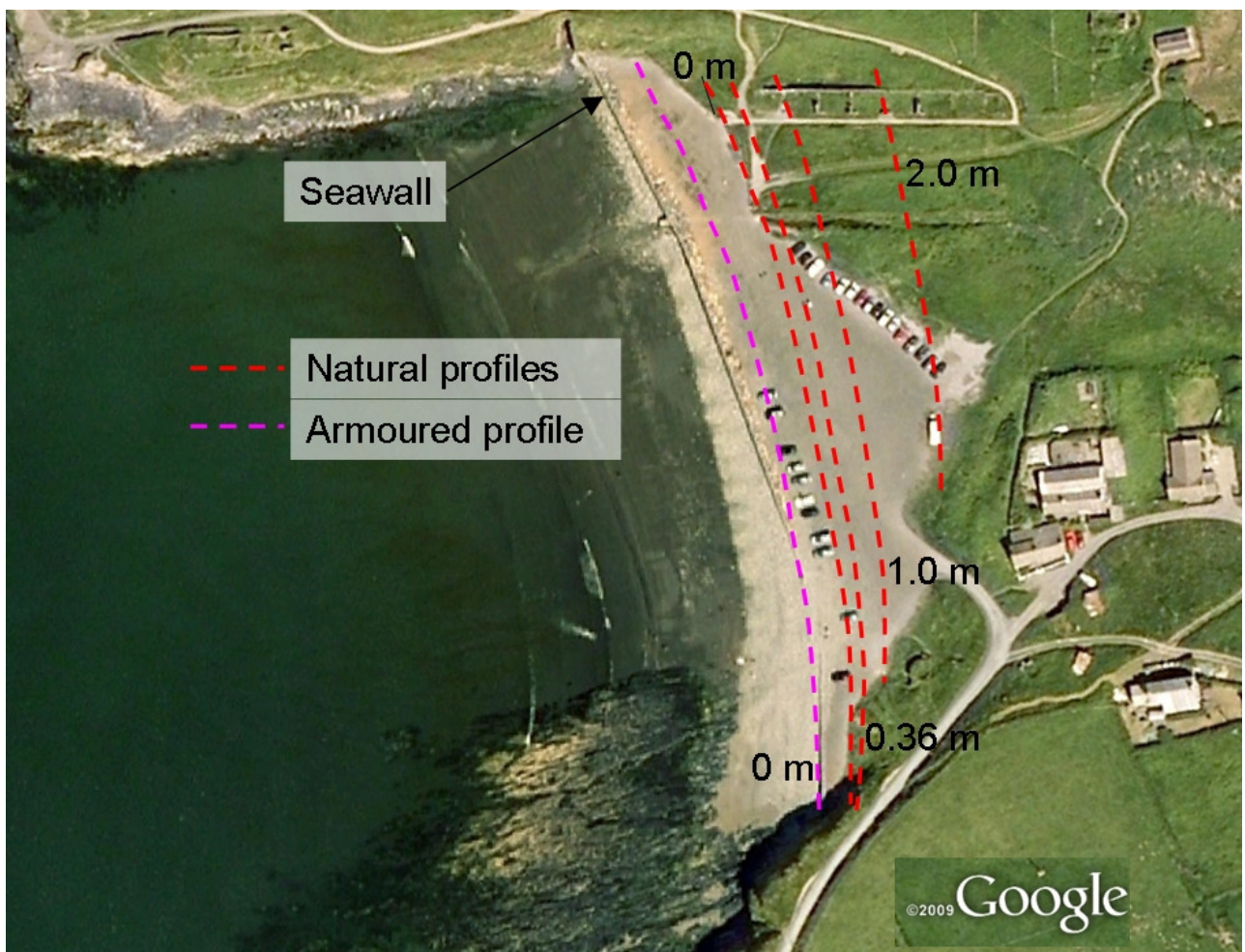

Fig. 3. Projected beach planforms under sea-level rise scenarios, the rise in sea level assumed in each case is indicated against each line

\subsection{Application of the Results}

In this case study the tendency of a beach to adopt a crenulate shape between two hard points was used to construct potential future three-dimensional beach forms at Abereiddy. Crenulate bay theory was particularly useful because the natural shape of the beach was largely masked by the presence of the seawall. 
The results are useful in two ways. First, they allow hazard identification, whereby the losses associated with each scenario can be assessed. For example, less than half of the car park would be expected to be lost following the failure of the seawall (without armouring the beach and before significant sea-level rise), whereas with a $2 \mathrm{~m}$ rise in sea level the car park would be lost, but the cottages behind the beach may not be directly eroded. Such information is crucial for cost-benefit analysis required for scheme justification. The results are equally useful in informing stakeholder consultation and the consensus building often necessary to allow good decision making in coastal management. By first projecting and then visualising future shorelines under each scenario, stakeholders can begin to understand the implications of management decisions and the 'natural' pressures on the coast like climate change.

\section{Coyote Point Beach, San Francisco Bay}

Coyote Point is a regional recreation area in San Francisco Bay and its coastal section is a popular destination for swimmers, windsurfers, kayakers, cyclists, and walkers. Its slightly concave north-facing coastal frontage is approximately $600 \mathrm{~m}$ long between a rock headland to the east and the point where the Bay Trail meets the coast to the west (Figure 4). The eastern section of the shoreline is restricted to swimmers and sunbathers, whereas the western section is used by windsurfers. Important amenities close to the shoreline include western and eastern car parks, a kite and windsurfing retail outlet located in the centre of the coastal section, and an animal rescue centre at the western extremity of the site.

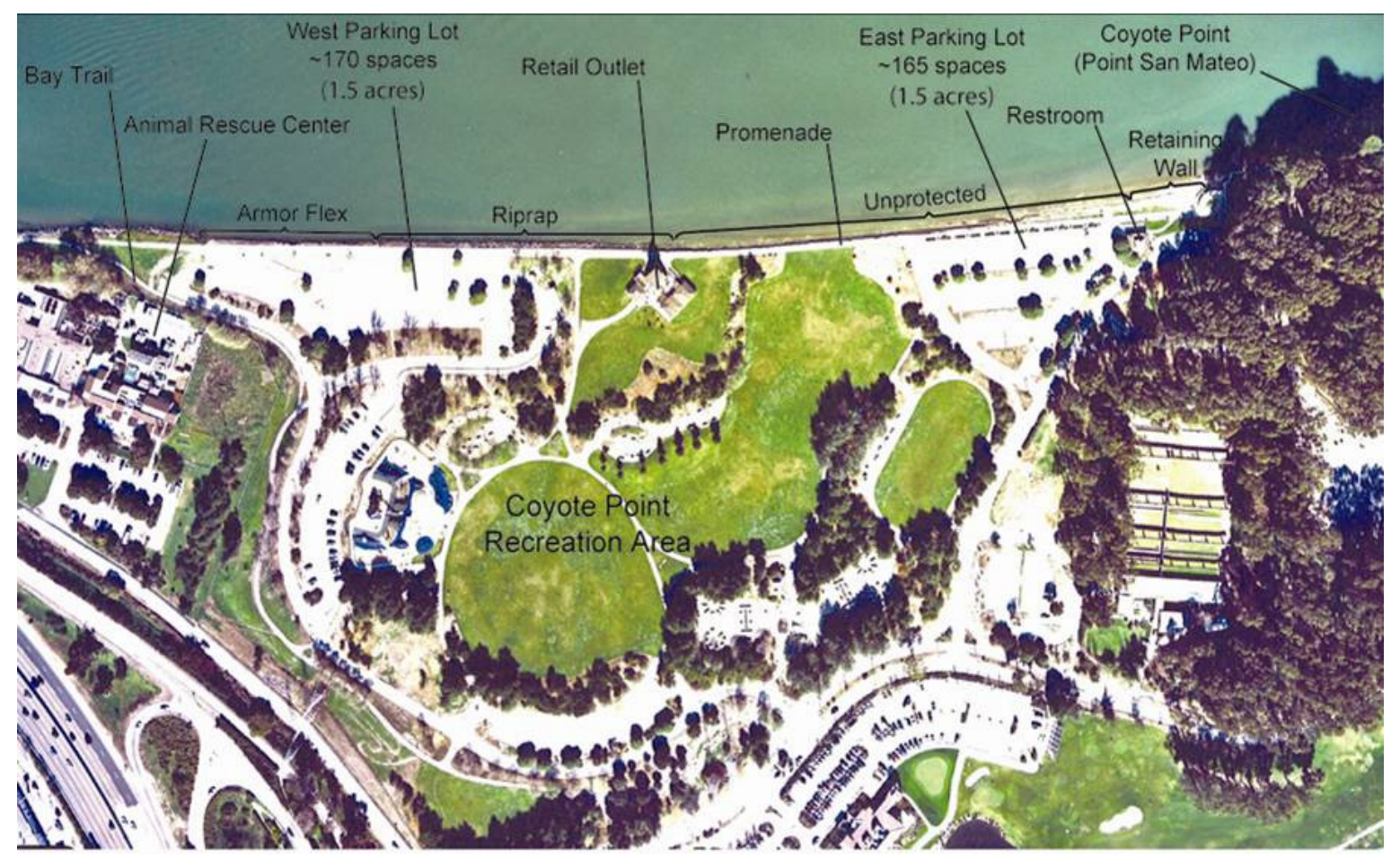

Fig. 4. Site map showing locations of coastal structures and amenities at Coyote Point 
In the 1990s a series of coastal structures were constructed along the frontage to provide erosion protection to the recreation area, and in particular to protect a pedestrian promenade adjacent to the beach (Figure 4). Presently, these structures are failing, leading to undercutting and damage to the seaward side of the promenade (Figure 5). A key question for management is how to develop a sustainable solution to the coastal erosion problem while maintaining park functions and facilitating good public access to the beach and water for a variety of users, particularly swimmers (east) and windsurfers (west).

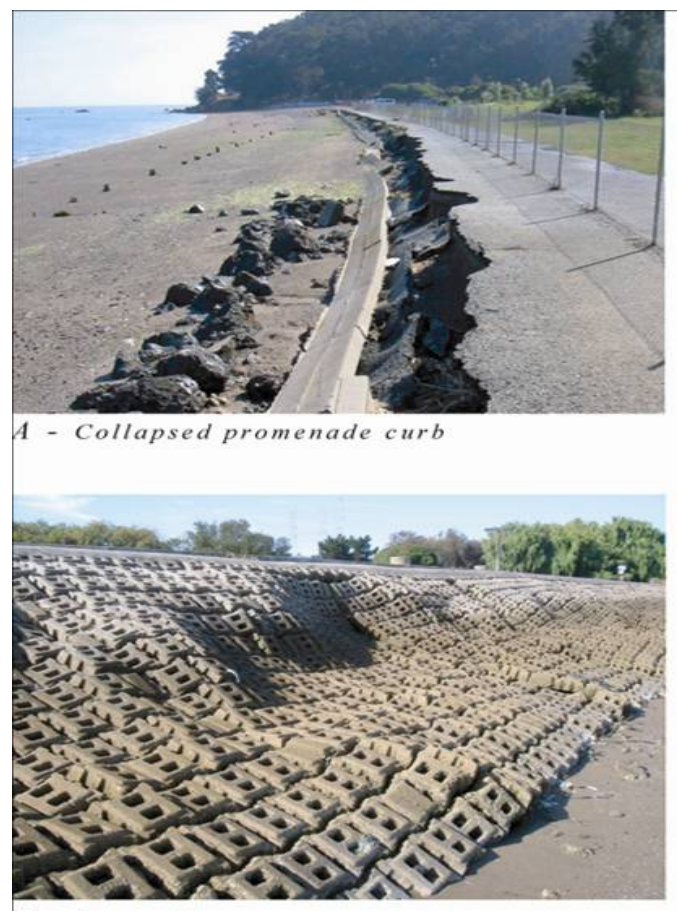

C - Armor Flex
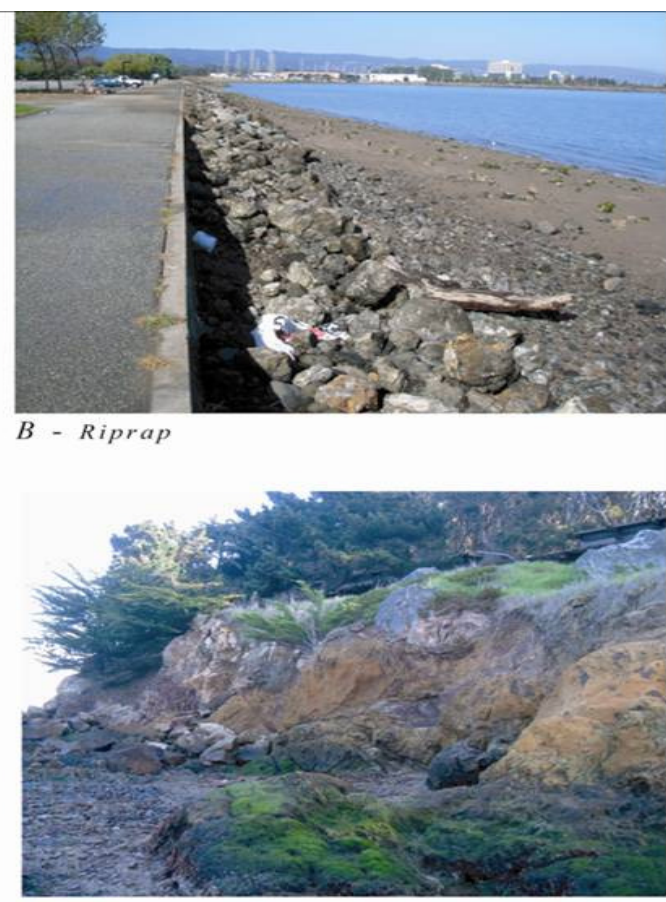

D - Bedrock (Point San Mateo)

Fig. 5. Photographs showing damaged structures along the Coyote Point frontage

\subsection{Erosion and the Planform}

The Coyote Point shoreline is eroding and unable to migrate landward with this process because it is constrained by the coastal structures. The stable planform position would be a crenulate bay. The structures hold the coastal planform in a position seaward of the position it would take if the shoreline was allowed to equilibrate with the physical processes controlling its shape. Recognizing the physical and sedimentary processes that are operating at the site a series of conceptual alternatives were developed, which entail creation of one or two crenulate bays between the Coyote Point headland and the Bay Trail.

\subsection{Conceptual Crenulate Bay Alternatives}

Several conceptual alternatives were developed each with a set of opportunities and constraints related to sustainability, public access to the beach and water, and loss of car parking spaces. No action and 'hold-the-line' alternatives were rejected because both are unsustainable. Both 
these alternatives would lead to continued erosion of the beach, exposure of the underlying substrate, loss of sand, and continued undermining and collapse of the coastal structures.

An alternative to remove all the existing structures and realign the whole shoreline between the Bay Trail and Coyote Point headland to a position setback from its current position was also not favoured. This would create a single large crenulate bay (Figure 6), resulting in loss of both car parking areas and a requirement to remove or relocate the promenade and all of the buildings along the coast. In addition, a wide sandy beach across the western portion of the frontage would be unfavourable for windsurfing access to the water.

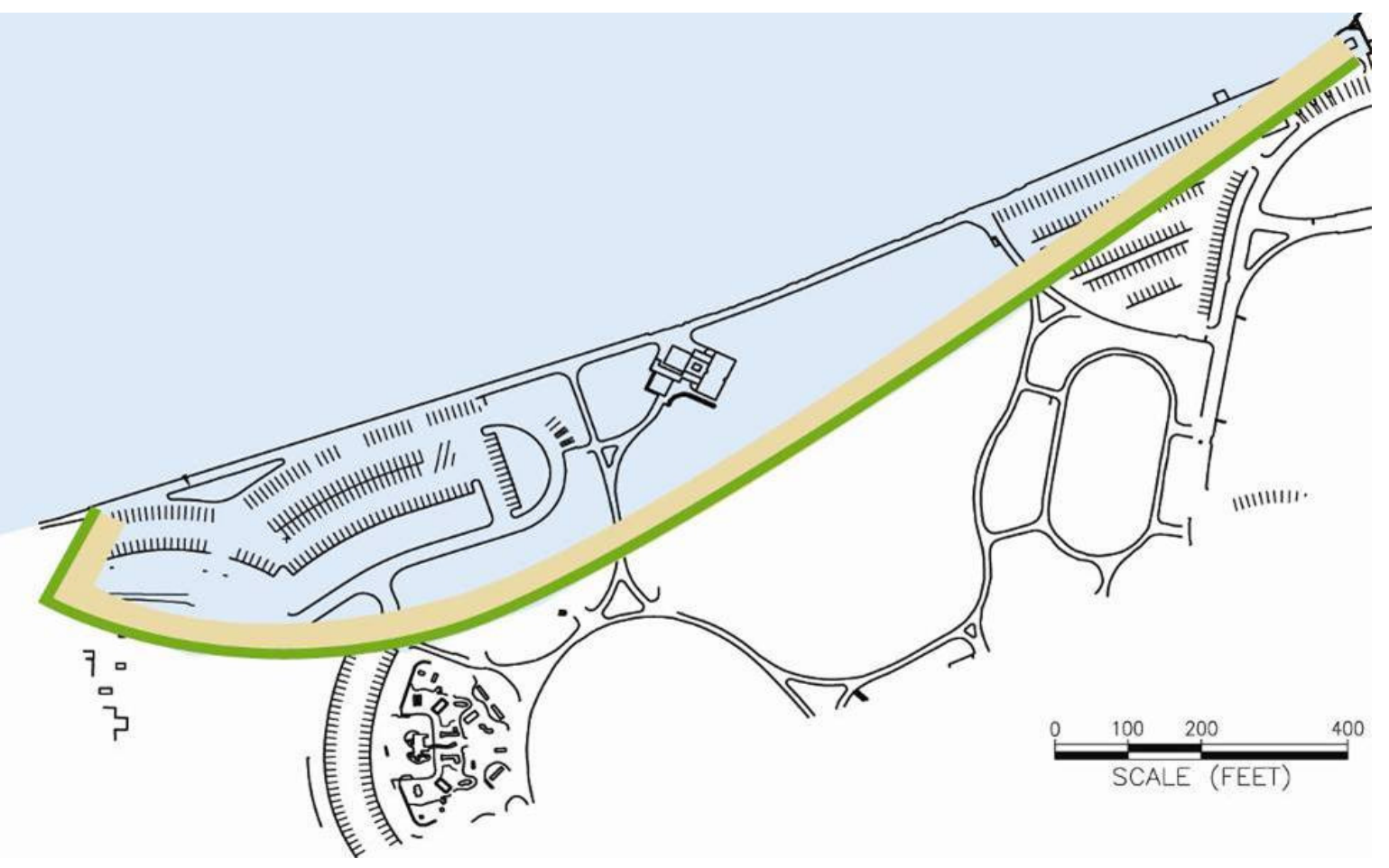

Fig. 6. Conceptual alternative to set back the entire shoreline

Other alternatives considered removal of existing structures and realignment of the western shoreline to a position setback from its current position between the Bay Trail and the retail outlet (Figure 7). Currently, the western section of the shoreline is restricted for the use of windsurfers who require space to rig their boards and sails, and prefer direct quick access to the water, without the need to cross a wide sandy beach. The existing condition west of the retail outlet is suitable for windsurfers because it meets the access criteria and there is suitable rigging space landward of the promenade. Creation of a crenulate bay-beach between the Bay Trail and the retail outlet would remove the rigging locations and would make access to the water more difficult. Because of the constraints to the windsurfing community, who are an important stakeholder in the management process at Coyote Point the creation of a crenulate bay along the western portion of the frontage was ruled out. 


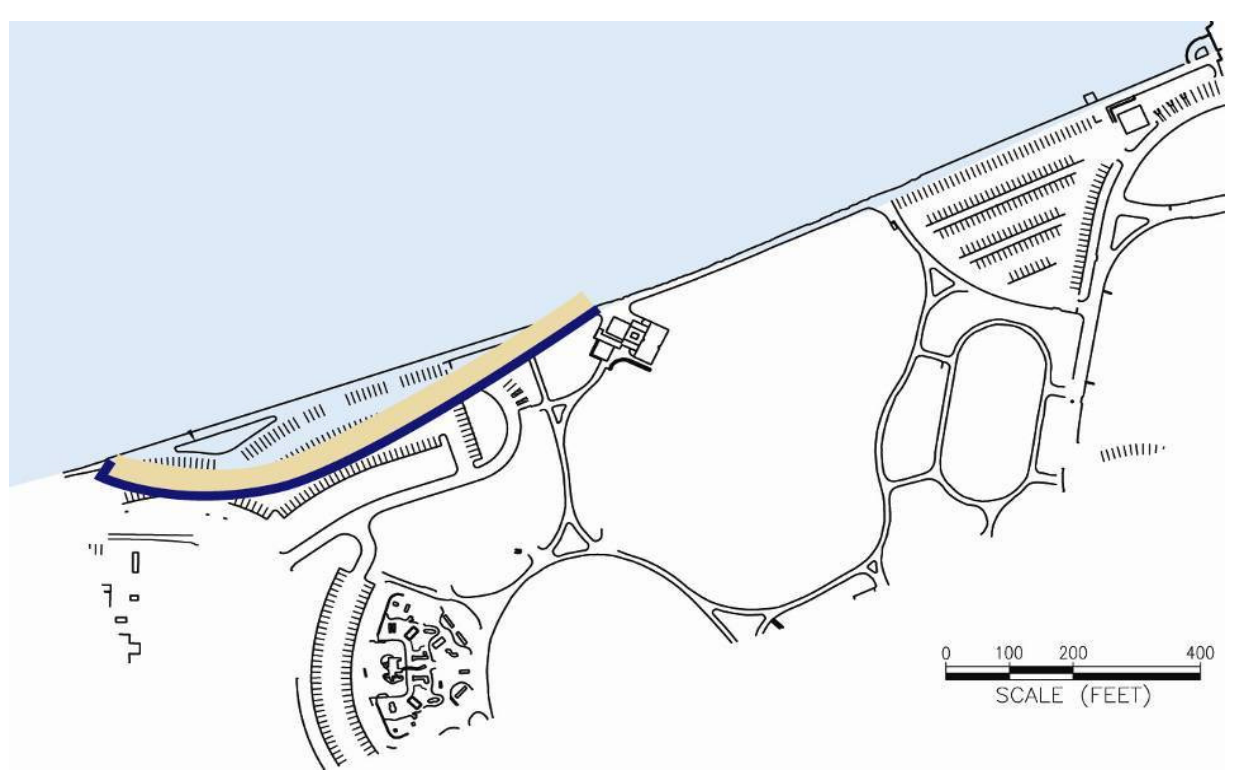

Fig. 7. Conceptual alternative to set back the western portion of the shoreline

\subsection{Preferred Alternative}

After consideration of all the opportunities and constraints, a preferred alternative was selected to remove the existing structures and realign the eastern shoreline to a position setback from its current position between the retail outlet and Coyote Point headland (Figure 8).

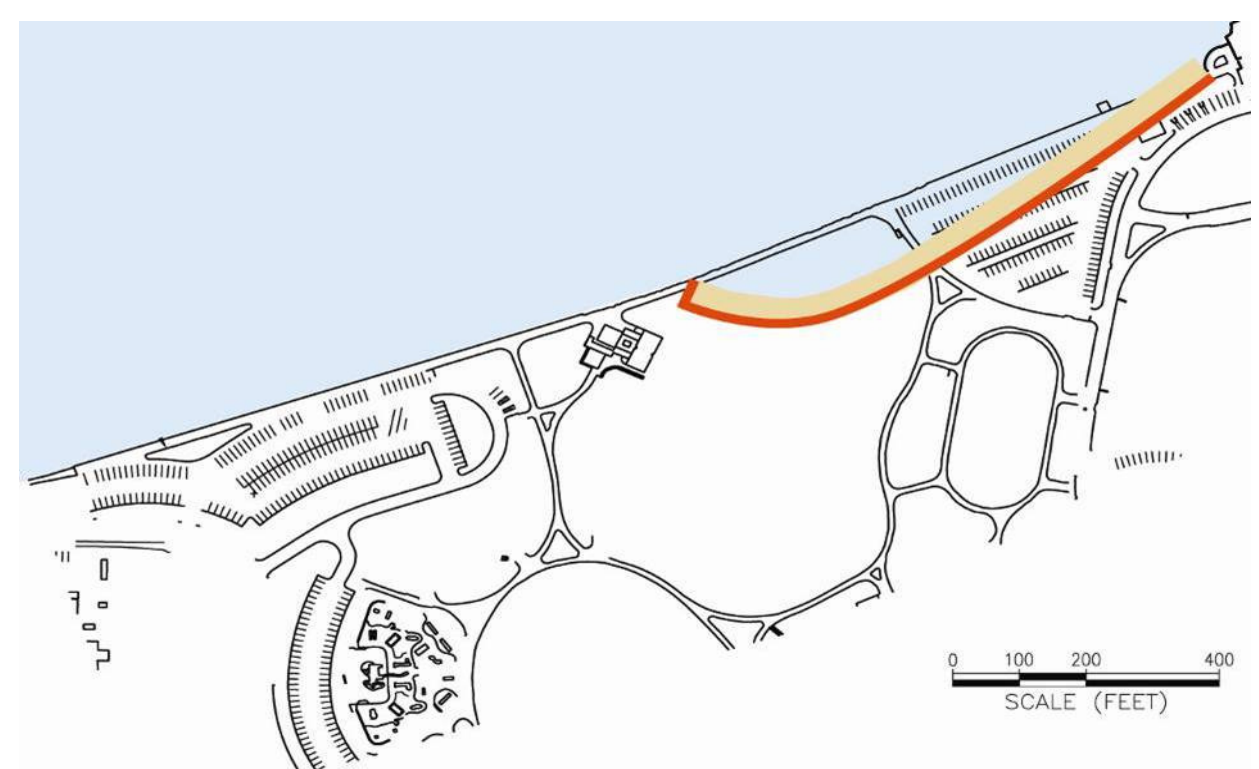

Fig. 8. Preferred conceptual alternative to set back the eastern portion of the shoreline 
The coastal structures to the west of the retail outlet would be maintained along their present alignment. The crenulate bay would be held in position by an artificial hard point located close to the retail outlet, and by Coyote Point headland. This alternative would be combined with beach nourishment within the crenulate shaped bay cell.

This alternative presents the best balance of opportunities and constraints, presuming that a new parking area is constructed to maintain existing levels of access. Access to the beach would be by steps from a promenade reconstructed along the landward edge of the crenulate bay. The beach would be used for recreational activities excluding windsurfing. Armouring the frontage west of the retail outlet, potentially in combination with access ramps, would provide a solution for windsurfers.

\subsection{Application of the Results}

In this case study, the value of crenulate bay theory is demonstrated by comparison of different bay configurations to develop the best and most sustainable design for coastal planform. The preferred crenulate bay design for the restoration of the Coyote Point shoreline mitigates the potential for future erosion and storm damages and meets the criteria posed by the initial question. It will extend the sustainability of the site through consideration of a stable shoreline configuration and the conceptual design provides good public access to the beach for swimmers (east) and windsurfers (west).

\section{Applications in Integrated Coastal Zone Management}

Shoreline management planning has been a developing process over the last two decades in the United Kingdom. Although the focus of the Shoreline Management Plan (SMP) is on establishing an appropriate approach to flood and coastal erosion risk, the essential driver in defining such an approach is developing a plan for balanced sustainability (Defra, 2006). In this way, the SMP considers the existing situation and creates a vision for the use of the coastal zone in terms of nature conservation, the economic value of existing assets, commercial and tourism use, and the inherent cultural and social values of coastal communities. The plan looks at the potential need to adapt existing use or to accommodate future use through interventions at the shoreline. Shoreline management is not integrated coastal zone management (ICZM) but provides one of the essential building blocks of ICZM, in defining what may be possible, what may not be sensible and what future vision may be sustainable.

Underpinning the SMP process is an understanding of the coast, with all the uncertainties associated with long-term prediction, climate change and existing uncertainties as to the behaviour of the coast. The previous case studies consider the relatively detailed application of crenulate bay theory at local scales. The following section takes this to more conceptual level, looking at how this theory can be used in examining broader-scale coastal behaviours over 10s of kilometres.

\subsection{Landscape Scales}

One of the basic tenets of the SMP process has been that the plan should be developed primarily on existing information. Where they are critical, further studies might be undertaken, 
and part of the role of the SMP is to identify where further study may be required. However, the basic approach is to draw together information that tests and challenges the consistency and coherence of our understanding over the whole coastal area.

In several areas more detailed study or research may have been undertaken in the past. Quite frequently this has focussed on local areas where there are specific issues for management; where there is seen to be good justification for more in-depth study. Along many stretches of the coast there is still limited information and even where detailed study has been carried out, the scope of detailed modelling, short-term monitoring and coastal processes assessment are considered in isolation from the bigger picture. Significant steps have been taken in looking at system analysis techniques to address this (French and Burningham, 2009), drawing together local process understanding of features and elements of coastal behaviour. Application of crenulate bay theory complements such approaches.

Looking at the planform allows similarities between coasts to be identified, allowing the conclusions from local detailed process studies to be extended, at a high level, to provide understanding of other areas of the coast. The differences between areas may also be highlighted, showing how disparate information can be drawn together to provide a coherent concept of behaviour. Figure 9 shows this in principle, using the existing shape of the coast to define an anticipated framework, which then highlights critical control features and perturbations within this idealised framework that may be critical to management.
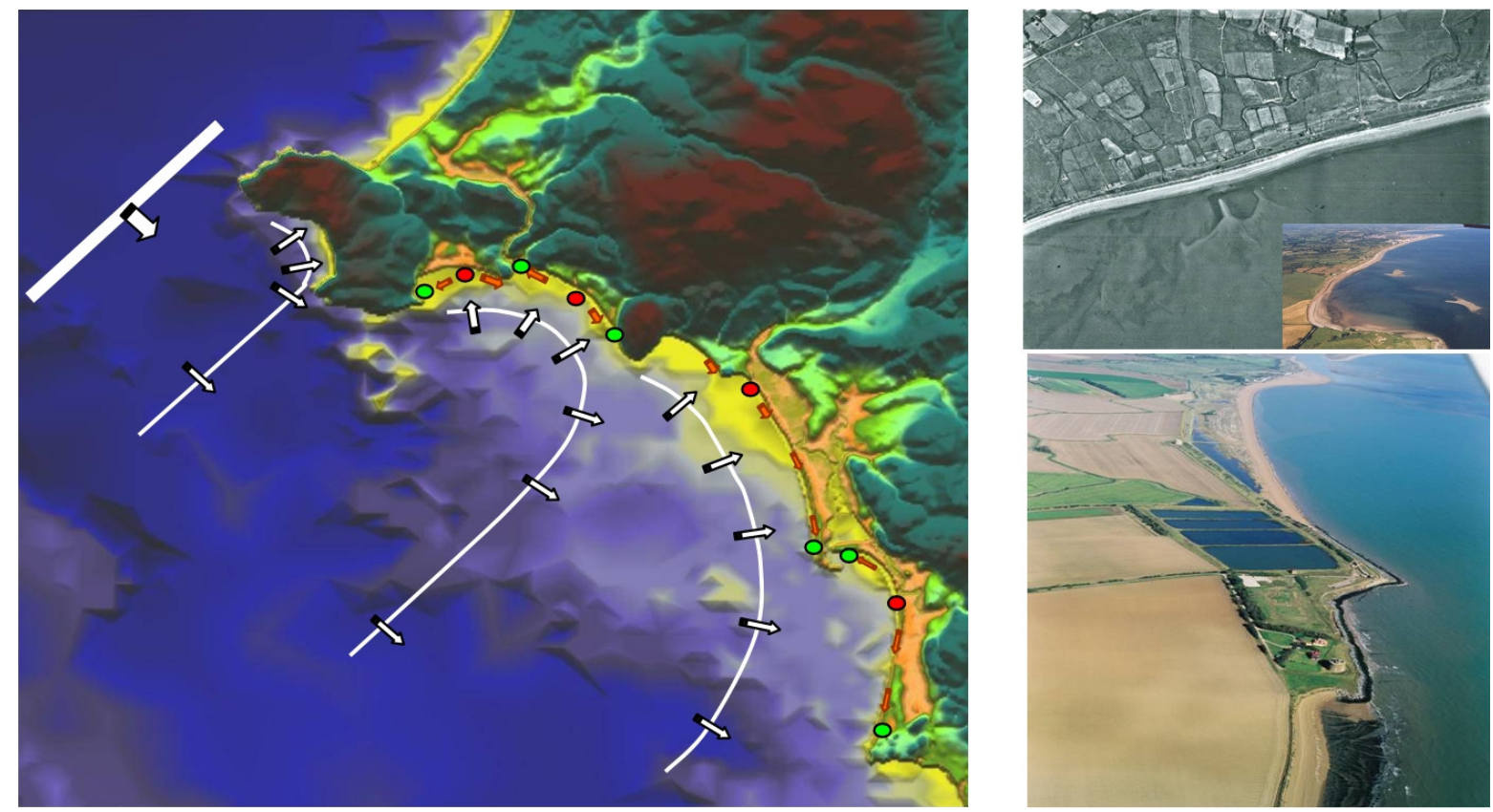

Fig. 9. The conceptual use of crenulate bay theory identifying critical behaviours of the coast 


\subsection{Future Management}

While there is a lot of good historical information, sophisticated modelling techniques, and in some areas monitoring data extending back 20 years, this has to be viewed from a perspective of 'cyclic' processes occurring over decades and geomorphological change working over centuries. In looking at management over the next 100 years and beyond, care needs to be taken in extending existing information as a baseline for the future. Figure 10 shows the pattern of change for a section of the Suffolk coast south of Benacre Ness.

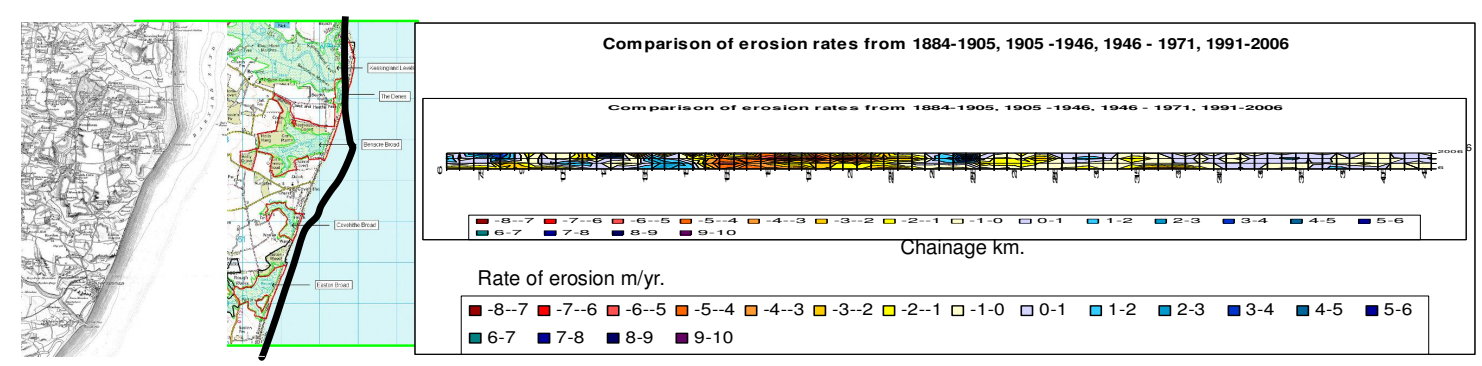

Fig. 10. Change in coastal form and erosion to the coast south of Benacre Ness, Suffolk.

As the Ness feature has moved north, so the coast to the south has been exposed to erosion. Historical rates of erosion have varied over time between $3 \mathrm{~m} / \mathrm{yr}$ to $10 \mathrm{~m} / \mathrm{yr}$. This raises the issue of future sustainability; is erosion likely to continue at these rates well into the future and are there approaches to management that may limit the extent of erosion? Examination of this, using basic crenulate bay theory (Figure 11), highlights that through natural development a more stable coastline may develop in 100 years, mirroring the behaviour of the Suffolk coast further south. It also allows consideration of possible management approaches in assessing the potential impact on sediment supply to the south, the impact of nature conservation interests and the viability in defending communities along this rapidly changing section of the coast. Although recognised to be simplistic, this examination identifies critical choices that need to be made, despite uncertainties as to actual timing. This provides the questions and the basic framework for taking forward broader coastal management. 


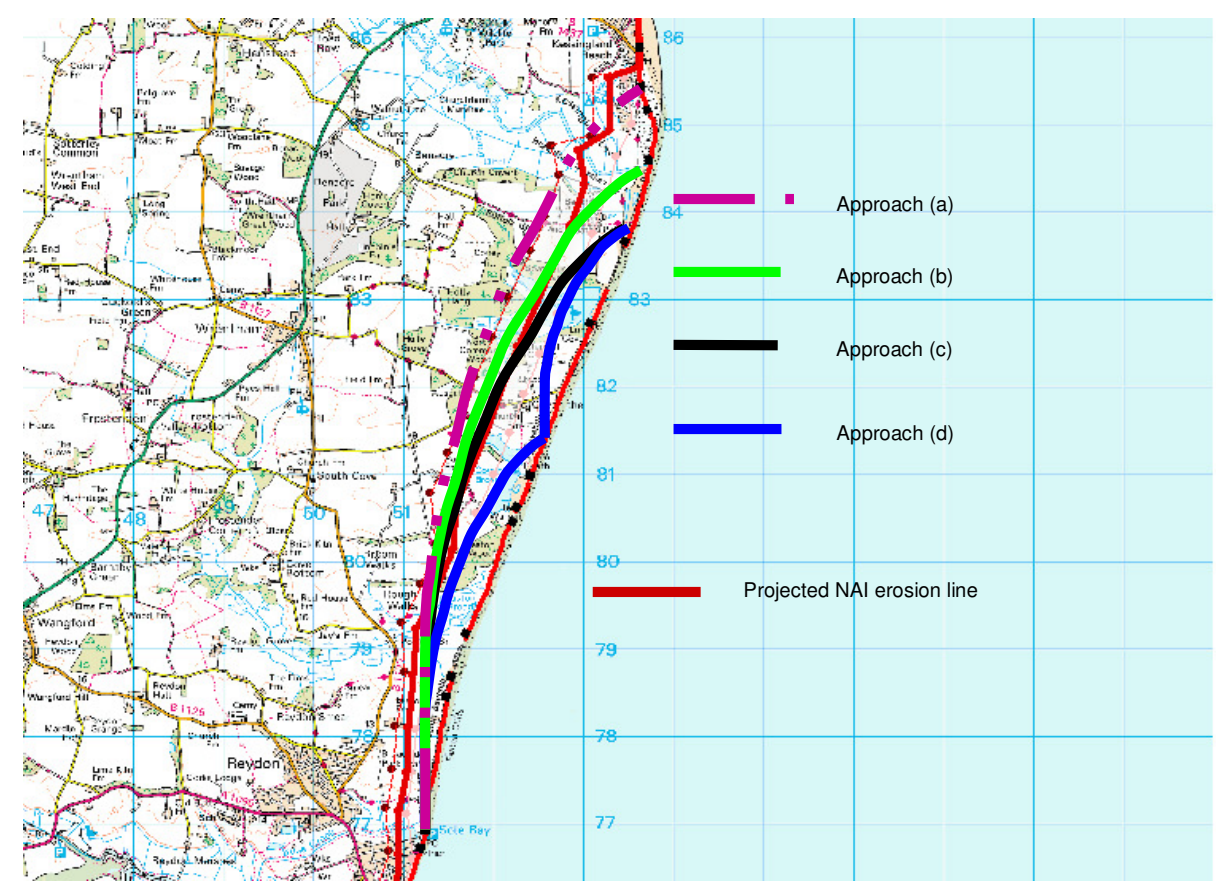

Fig. 11. Comparison of baseline erosion projection and different approaches to management.

\section{Conclusions}

Three very different applications of crenulate bay theory have been described in the paper, from a detailed numerical beach volume analysis in the case of Abereiddy, through the kilometre scale at Coyote Point, to examination of coastal behaviour over 10s of kilometres in developing SMPs.

So is crenulate bay theory a panacea for all coastal management? Quite evidently not. However, one of the strengths identified in the broad-scale SMP assessment is identifying where the coast behaves differently from that which might be anticipated from high-level theory. It is through further examination of such areas that the real nature of the coast is revealed. Such system analysis does set boundaries within which critical aspects of the decision-making process can be explored. In the case of Abereiddy, the crenulate bay approach allowed a basic structure within which more detailed process analysis could be undertaken. In the case of Coyote Point, the approach provided outline options, within which the much harder decisions of adapting use and a vision for the area still need to be taken.

Practical coastal decision making will involve assessment of future coastal change. Part of understanding the consequences comes from understanding the underlying principles of coastal behaviour. In stepping back from the detail, to more simplified explanations based on what people actually observe on the coast, it becomes possible to give communities an understanding of opportunities in addition to the risks and constraints. This helps them to become involved with the decisions that need to be made. 
The coast would be awfully complex if it were not so simple. The need for in-depth understanding remains essential. However, a broader view provides a context within which that detailed understanding can be applied commensurate with the problems being addressed. Our case studies demonstrate this, and show that because crenulate bay theory captures a fundamental behaviour of certain beach shorelines, it enables rapid prediction of their future development. Furthermore, the case studies show that this predictive strength can be harnessed to address issues at a wide range of scales.

\section{References}

Defra. 2006. Shoreline Management Plan Guidance Volumes $1 \& 2$.

French, J. and Burningham, H., 2009. Mapping the connectivity of large-scale coastal geomorphological systems. Coastal system mapping with the Cmap Tools tutorial. Environment Agency Project Record - SC060074/PR.

Halligan, G., 1906. Sand movement on the New South Wales Coast. Proceedings of the Linnean Society of New South Wales, 31, 619-40.

Hsu, J.R.C., Benedet, L., Klein, A.H.F., Raabe, A.L.A., Tsai, C.P. and Hsu, T.W., 2008. Appreciation of static bay beach concept for coastal management and protection. Journal of Coastal Research, 24, 198-215.

Silvester, R., 1960. Stabilisation of sedimentary coastlines. Nature, 188, 467-469.

\section{Acknowledgements}

We would like to thank County of San Mateo Parks and Recreation Department for permission to publish the conceptual ideas for Coyote Point. The authors would like to thank the Environment Agency for provision of LiDAR data for the Abereiddy area, and Pembrokeshire County Council who commissioned the Abereiddy study. 